\title{
A EDUCAÇÃO AMBIENTAL COMO ARTICULADORA DOS SABERES E FAZERES DO MAR NAS ESCOLAS DO CAMPO DAS ILHAS DO LITORAL DO PARANÁ
}

\section{ENVIRONMENTAL EDUCATION AS ARTICULATOR OF THE KNOWLEDGE AND PRACTICE OF THE SEA IN THE RURAL SCHOOLS OF THE PARANÁ COAST ISLANDS}

\author{
Vanessa Marion Andreoli ${ }^{1}$ \\ Lilian Medeiros de Mello ${ }^{2}$
}

\section{RESUMO}

Compreendendo a Educação ambiental crítica como potencializadora do diálogo de saberes, da valorização e do fortalecimento comunitário, este texto traz o relato da experiência de um projeto de extensão, atualmente em curso, desenvolvido junto às comunidades das Ilhas do litoral paranaense atendidas por Escolas do Campo. Temse a escola como um espaço no qual é necessário criar situações que possibilitem o aprofundamento de temáticas oriundas das realidades socioambientais locais. Durante a primeira fase do projeto foi realizado um diagnóstico participativo nas nove escolas de Ensino Fundamental (de Sexto a Nono Ano) e Médio em funcionamento nas ilhas do Paraná. Foi possível identificar as principais problemáticas e interesses locais, assim como as demandas que possibilitam adequar a proposta formativa a cada realidade. Verificou-se que o professor, como mediador do processo educativo, necessita articular o currículo com a prática social dos estudantes e das comunidades. Para tanto, o projeto prevê a construção coletiva de materiais didáticos que contemplem a realidade socioambiental de cada região, assim como os saberes e fazeres locais aliados ao currículo.

Palavras Chave: Educação ambiental crítica; Educação do campo; Oceanografia socioambiental; Saberes e fazeres do mar; Formação continuada; Extensão universitária.

\footnotetext{
1 Prof $^{\text {a }}$ do Setor Litoral da Universidade Federal do Paraná, Matinhos, PR vanessaandreoli.ufpr@gmail.com

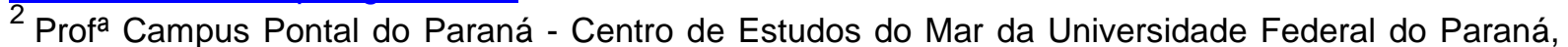
Pontal do Paraná, PR. mellolilian@ufpr.br
} 


\begin{abstract}
Understanding Critical Environmental Education as a potentiator of the dialogue of knowledge, valorization and community empowerment, this text presents the experience of an extension project, currently underway, developed with the communities of the Parana Coastal Islands served by Rural Schools. The school is understood as a space in which it is necessary to create situations that allow the deepening of themes from the local socio-environmental realities. During the first phase of the project, a participatory diagnosis was carried out in the nine elementary schools (from 6th to 9th grade) and high schools operating in the islands of Paraná. It was possible to identify the main issues and local interests, as well as the demands that make it possible to adapt the formative proposal to each reality. It was found that the teacher, as a mediator of the educational process, needs to articulate the curriculum with the social practice of students and communities. To this end, the project foresees the collective construction of didactic materials that contemplate the socio-environmental reality of each region, as well as local knowledge and practices combined with the curriculum.
\end{abstract}

Keywords: Critical environmental education; Rural education; Socioenvironmental oceanography; Knowledge and practices of the sea; Continuing formation; University extension.

\title{
INTRODUÇÃO
}

No Paraná, as comunidades de ilhéus vêm sofrendo fortes pressões a partir da criação, nos anos de 1980, das chamadas Unidades de Conservação, cujo modelo de implantação interfere nos direitos de reprodução dos modos de vida dos povos e comunidades tradicionais presentes nestes locais (Faraco et al., 2016).

Em um contexto marcado pela desconsideração de um conjunto de direitos humanos, sobretudo das comunidades do campo, como é o caso dos ilhéus, a educação formal torna-se um importante instrumento de emancipação dos sujeitos. Para tanto, é necessário que a escola possibilite o acesso a um conjunto de conhecimentos que são elaborados e vivenciados pelos ilhéus.

Esses saberes e fazeres envolvem as maneiras próprias de viver e se relacionar com o mar, a pesca, a terra, o céu, as marés, as lendas, os costumes, as danças, as crenças, etc. Para que se tenha alguma garantia de que esse conjunto de conhecimentos seja passado de geração em geração, é necessária a valorização e a resistência de uma identidade que lhes é própria.

O Litoral do Paraná conta hoje com 10 colégios estaduais localizados nas ilhas que apresentam diversos e complexos desafios enfrentados cotidianamente, tanto político/administrativos, quanto didático/pedagógicos. Um dos desafios das 
escolas nessas regiões é reafirmar os vínculos de pertencimento dos estudantes ao território em que vivem. Entende-se que o constante diálogo entre saberes escolares e não escolares pode permitir canais para a construção de estratégias de sobrevivência, resistência, emancipação e mesmo de superação de problemas.

Sendo a extensão universitária uma forma de contribuir com a transformação social, por meio da participação conjunta na construção de novos conhecimentos, o projeto de extensão "Saberes e Fazeres do Mar: diálogos entre o currículo e a realidade local nas escolas das ilhas do litoral paranaense" propõe a presença da universidade, a partir de uma formação continuada contextualizada, considerando a valorização dos saberes e fazeres do mar e o aprofundamento de assuntos específicos que tratam das realidades socioambientais locais.

A expressão "Saberes e Fazeres do Mar", que dá nome ao projeto de extensão aqui relatado, flerta com a definição de Berkes (1999, citado por Kalikoski et al., 2006) de Conhecimento Ecológico Tradicional, que "abrange o conjunto de informações, interesses e valores da relação entre a comunidade local e o meio ambiente de que fazem parte, transmitido através de gerações". Por relacionar-se com comunidades pesqueiras (Mendonça et al., 2017) apoia-se também na perspectiva etnooceanográfica (Moura, 2009), que compreende o conhecimento do território e seus processos no e do tempo/espaço marítimos.

A ideia do projeto em questão surgiu a partir de demandas identificadas por meio de pesquisas e inserções de professores e estudantes da Universidade Federal do Paraná em algumas escolas e comunidades das ilhas, a partir de 2013, mais especificamente dos cursos de graduação em Educação do Campo (Setor Litoral) e Oceanografia (Campus Pontal do Paraná - Centro de Estudos do Mar). Em 2017. O projeto foi registrado na Pró-Reitoria de Extensão e Cultura da UFPR e, no mesmo ano, ingressou como um componente da proposta "Vulnerabilidades e respostas das populações locais às ameaças socioeconômicas e naturais na Baía de Paranaguá - PR" (CNPq - Chamada Pública: Pesquisa e desenvolvimento em ações integradas e sustentáveis nas Baías do Brasil, Processo: 441591/2017-5). Hoje conta com uma equipe interdisciplinar de professores, bolsistas e técnicos da universidade, além da parceria com a Secretaria de Estado da Educação do Paraná (SEED). 


\section{A PROPOSTA PEDAGÓGICA DAS ESCOLAS DAS ILHAS DO LITORAL PARANAENSE}

A proposta pedagógica que orienta atualmente a organização das escolas da rede estadual do Paraná localizadas em llhas teve seus primeiros movimentos a partir de 2004, quando a SEED, por meio do Núcleo Regional de Educação de Paranaguá, criou o projeto Escolas das Ilhas, com a finalidade de garantir a oferta regular dos anos finais do ensino fundamental em todas as escolas localizadas em ilhas do estado do Paraná.

A partir de reuniões técnicas e tomando como premissa as Diretrizes Curriculares para a Educação do Campo do Paraná (2006) e a Política Nacional de Desenvolvimento Sustentável dos Povos e Comunidades Tradicionais do Brasil (2007), em uma parceria estabelecida entre a SEED (por meio do Núcleo Regional de Educação), a Universidade Federal do Paraná - Setor Litoral e alguns coordenadores das escolas das llhas, foi elaborada uma proposta experimental específica para essas escolas, intitulada de "Proposta pedagógica das Escolas das Ilhas do Litoral Paranaense", em 2009.

A ideia era a de que o documento, permeado pela concepção da Educação do campo, influenciasse a escola na "sua organização curricular e as práticas pedagógicas com vistas a uma práxis transformadora” (Paraná, 2009: 21). documento traz o papel preponderante da escola no processo da revalorização e socialização dos saberes dessas comunidades que podem, como bem traz proposta, "propiciar a elaboração e a implementação de políticas públicas e práticas pedagógicas ambientais menos impactantes aos ecossistemas regionais, que podem desdobrar-se na ampliação do desenvolvimento social" (Paraná, 2009: 15). Nesse sentido, ressalta-se a importância do diálogo entre os saberes tradicionais e da escola.

Propõe, então, uma nova organização curricular, compreendendo que "todo o conjunto de ações, pessoas e instâncias na e da escola devem ser transformados" (Paraná, 2009: 32), a fim de torná-la coerente com seus objetivos pedagógicos e não se resumir apenas à indicação de conteúdos desvinculados da realidade. Nesse contexto, a proposta percebe todo o entorno da escola (áreas de lazer, comércio, praias, etc.) como seu prolongamento, ou seja, esses espaços são vistos como 
educativos e, portanto, fazem parte dos saberes tradicionais da comunidade e devem ser considerados, tanto na organização do trabalho pedagógico da escola, quanto na gestão democrática, que "deve levar em consideração a participação da comunidade em todas as suas ações, haja vista que o processo educativo em questão compõe a formação de seus filhos" (Paraná, 2009: 34).

A matriz curricular proposta foi organizada por eixos temáticos, ligados aos modos de vida dos ilhéus, que buscam dialogar com as áreas do conhecimento e elencar conteúdos estruturantes a partir dessa relação (Figura 1).

Figura 1 - Eixos temáticos e sua relação com as áreas do conhecimento.

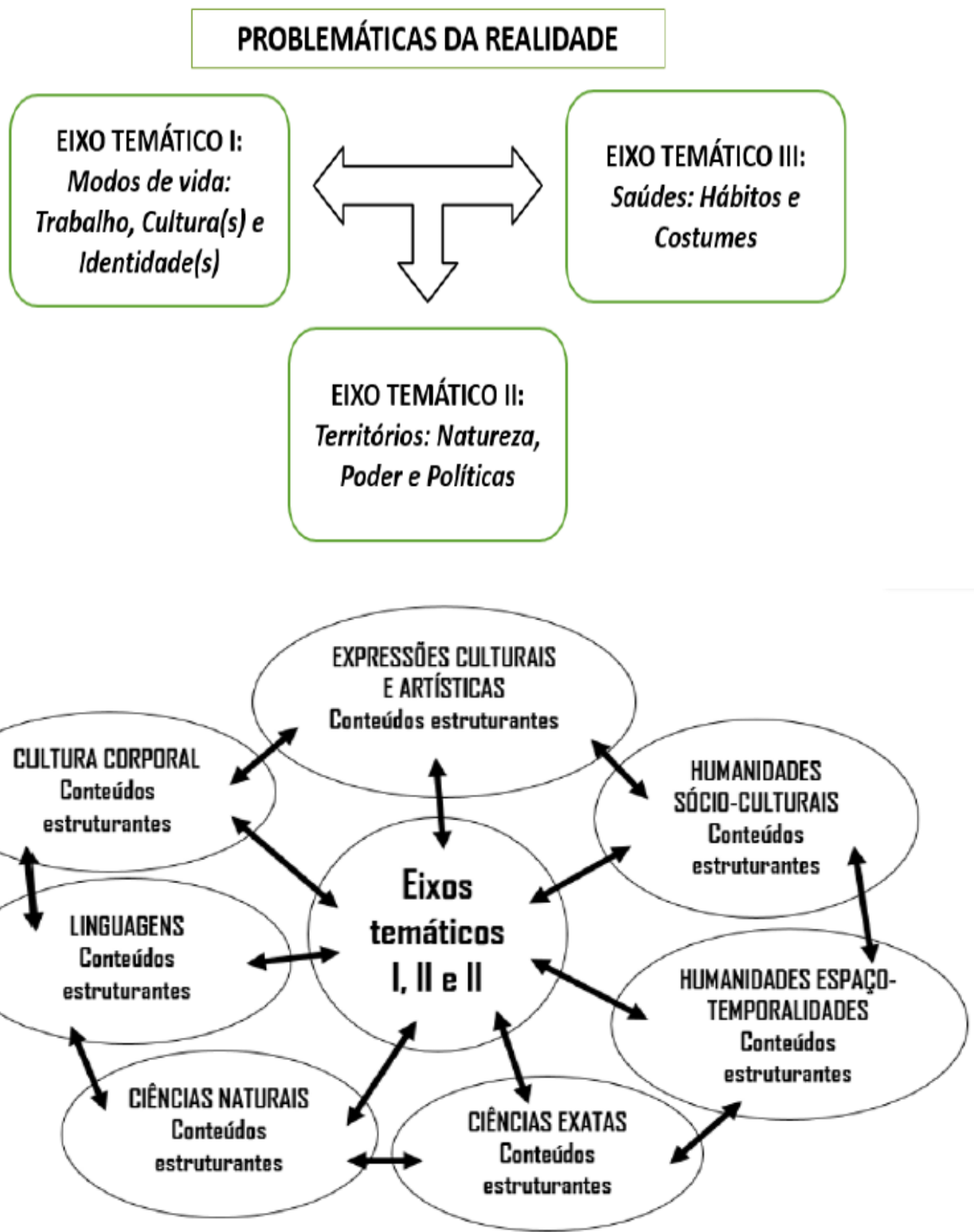

Fonte: Paraná (2009: 40). 
Em relação à formação dos professores, que é o foco principal do projeto de extensão aqui compartilhado, a proposta traz a importância da promoção de um intenso diálogo e reflexão sobre as interfaces dos saberes tradicionais e escolares e, para tanto, indica a necessidade da instalação de horas de trabalho junto à comunidade, no Tempo-Espaço Comunidade, alertando ainda que essa formação, entendida como reflexão coletiva das práticas pedagógicas, se realize como política pública. Por conta de mudança de gestão do Estado do Paraná, a formação não se efetivou na prática e, dessa forma, em inserções anteriores nessas escolas, foi possível constatar que os professores enfrentam muitas dificuldades por conta dessa nova organização curricular por áreas do conhecimento. Essas dificuldades são oriundas, principalmente, da formação inicial que tiveram, uma vez que os cursos de Licenciatura, no geral, estão organizados por disciplinas, de forma fragmentada, o que limita, ou mesmo impede, que os professores transitem pelos temas das disciplinas nas quais não são licenciados, mas que compõem a área do conhecimento em que atuam.

\section{O PROJETO “SABERES E FAZERES DO MAR”}

A partir do contexto apresentado, o projeto aqui relatado tem como objetivo geral contribuir com a formação continuada dos professores das ilhas do litoral paranaense e suas comunidades escolares no que se refere aos desafios da organização curricular por área do conhecimento, considerando a valorização dos saberes e fazeres do mar e o aprofundamento de assuntos específicos que tratam das realidades socioambientais locais. As escolas atendidas, neste primeiro momento, fazem parte da Rede Estadual de Educação do Paraná (Figura 2). 
Figura 2 - Comunidades/escolas atendidas pelo projeto Saberes e Fazeres do Mar (UFPR).

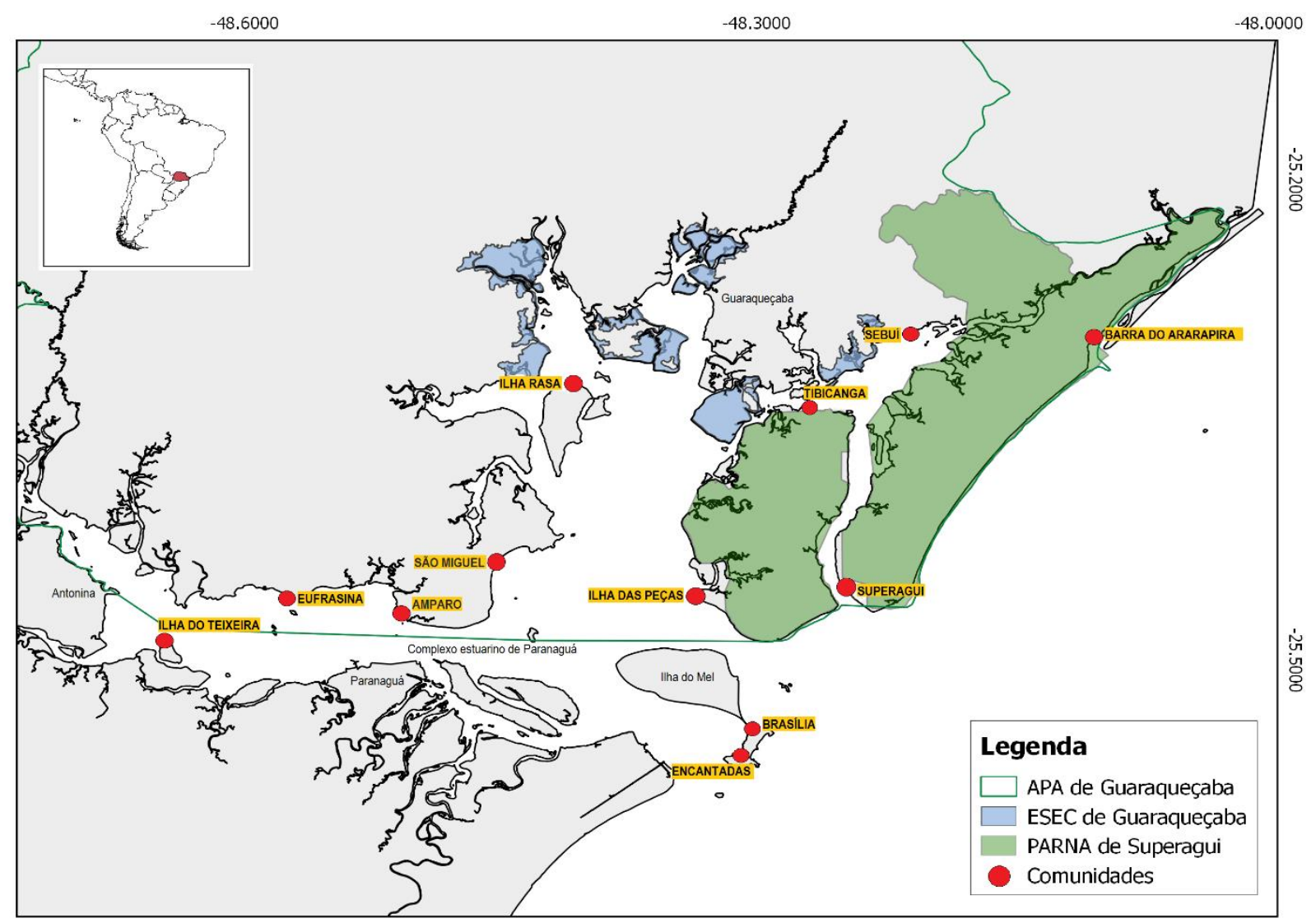

Fonte: Elaboração própria.

Considerando a extensão universitária como função social da Universidade pública, optou-se pela metodologia da pesquisa-ação, mais especificamente a Pesquisa colaborativa (Ibiapina, 2008), que visa aproximar duas dimensões da pesquisa em educação: a formação contínua de professores e a produção de saberes, o que privilegia a pesquisa e ao mesmo tempo a formação.

Essa junção permite avançar tanto na direção dos conhecimentos produzidos na universidade quanto na escola: ao se abordar questões, tanto de ordem prática quanto teórica, vinculadas à realidade, mobilizam-se situações nas quais é preciso tomar decisões quanto ao agir profissional dos estudantes em formação envolvidos. Dessa forma, a Pesquisa colaborativa é uma prática que se volta para a resolução dos problemas concretos, especialmente, no caso do presente projeto, aqueles vivenciados na escola, contribuindo com a disseminação de atitudes que motivam a 
coprodução de conhecimentos voltados para a mudança da cultura escolar e para o desenvolvimento profissional dos professores e estudantes.

Em síntese, o que ocorre nesse tipo de metodologia é a interação entre as múltiplas competências de cada um dos participantes: os professores com seu potencial de análise dos desafios da prática pedagógica (necessidades formativas) e os pesquisadores com seu potencial de formadores e organizadores de etapas formais de trabalho. Nesse sentido, investigar colaborativamente significa envolver pesquisadores (universidade) e professores (escola) em projetos comuns que beneficiem a escola e o desenvolvimento profissional docente.

O projeto compreende quatro fases (Figura 3).

Figura 3 - Desenho metodológico do projeto/previsão das fases.

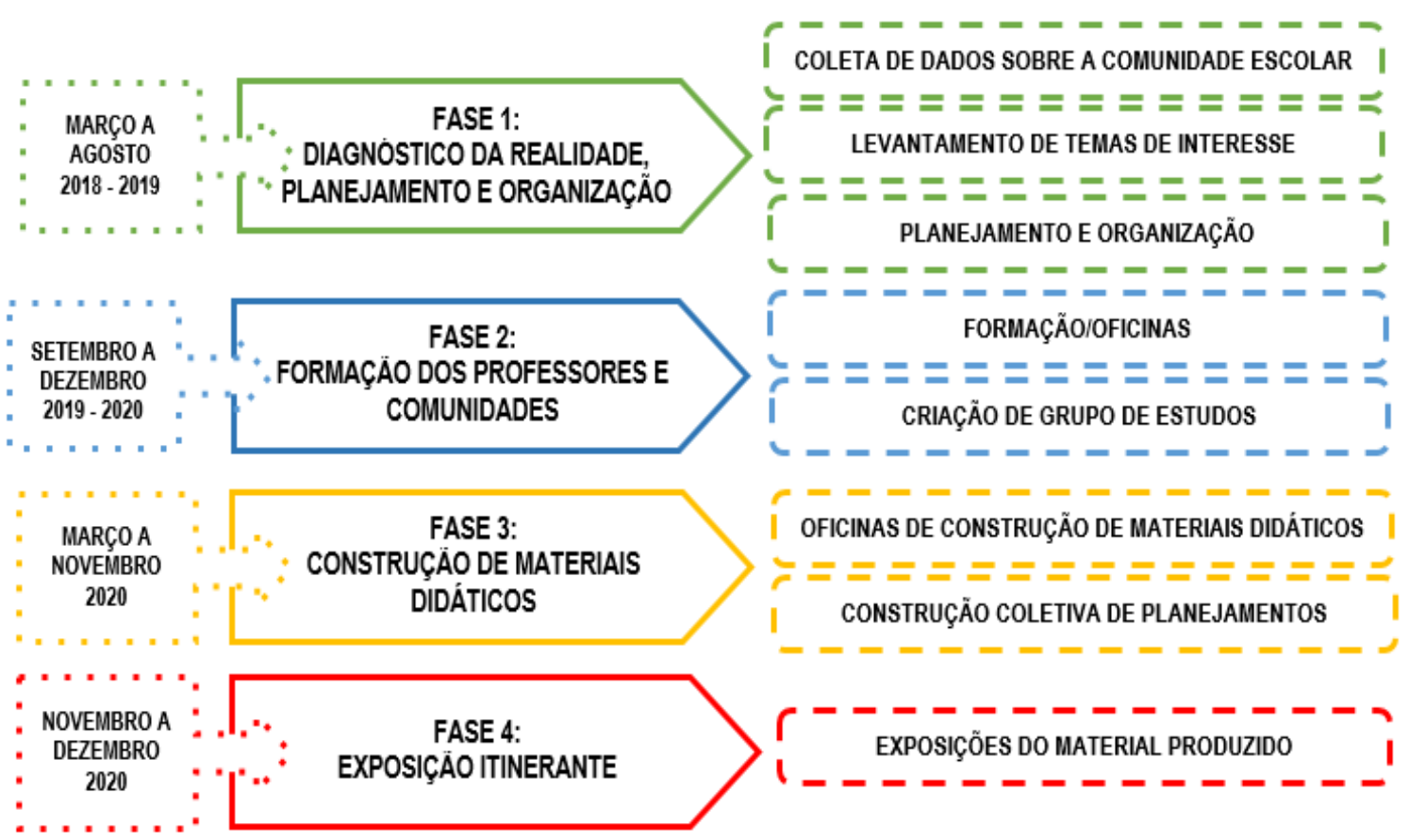

Fonte: Elaboração própria.

A primeira fase foi fundamental para todo o planejamento das ações seguintes. Partindo dos princípios da Educação do Campo, que considera que nenhuma proposta apresentada às escolas deve vir pronta, mas sim construída com os sujeitos envolvidos, entre maio e dezembro de 2018, o projeto realizou reuniões junto às comunidades escolares das Ilhas, a fim de reconhecer suas realidades e demandas formativas, mapeando possíveis ações pedagógicas conjuntas, 
considerando as áreas do conhecimento, os saberes e fazeres do mar e metodologias diferenciadas.

A primeira fase foi dividida em quatro etapas (Quadro 1).

Quadro 1 - Etapas da primeira fase do projeto Saberes e Fazeres do Mar (UFPR).

\begin{tabular}{|c|c|c|}
\hline \multicolumn{3}{|c|}{ FASE 1} \\
\hline ETAPAS & OBJETIVO & AÇÕES \\
\hline 1 & $\begin{array}{l}\text { Realizar um diagnóstico descritivo da } \\
\text { organização e estrutura escolar, bem } \\
\text { como prévio conhecimento acerca das } \\
\text { comunidades e seu entorno. }\end{array}$ & $\begin{array}{l}\text { 1. Formulário às direções com questões } \\
\text { sobre: a) Dados básicos da escola; b) } \\
\text { Estrutura física da escola; c) Quadro de } \\
\text { pessoal; d) Organização administrativa; e) } \\
\text { Organização pedagógica; f) e } \\
\text { Comunidade. } \\
\text { 2. Análise do Projeto Político Pedagógico e } \\
\text { de dados da Secretaria de Educação do } \\
\text { Paraná. } \\
\text { 3. Reuniões com os diretores das escolas } \\
\text { e Núcleo Regional de Educação de } \\
\text { Paranaguá. }\end{array}$ \\
\hline 2 & $\begin{array}{l}\text { Identificar os principais desafios } \\
\text { (fragilidades e potencialidades) da } \\
\text { prática cotidiana da escola, mapeando } \\
\text { possíveis ações pedagógicas entre as } \\
\text { áreas do conhecimento, os saberes e } \\
\text { fazeres locais e metodologias } \\
\text { diferenciadas. }\end{array}$ & $\begin{array}{l}\text { Oficina ministrada aos professores no } \\
\text { evento Interllhas, a partir da } \\
\text { problematização: Que escola temos e que } \\
\text { escola queremos? }\end{array}$ \\
\hline 3 & $\begin{array}{l}\text { Apresentar a proposta e acolher } \\
\text { sugestões/contribuições sobre o } \\
\text { desenho da formação continuada, a fim } \\
\text { de adequá-la a cada realidade e } \\
\text { interesses locais. }\end{array}$ & $\begin{array}{l}\text { Reuniões/processos de consulta com os } \\
\text { professores e estudantes das escolas e } \\
\text { com as comunidades (famílias, lideranças, } \\
\text { associações, movimentos sociais, e } \\
\text { instituições que fazem parte da dinâmica } \\
\text { comunitária da região). }\end{array}$ \\
\hline 4 & $\begin{array}{l}\text { Refletir sobre os dados levantados, } \\
\text { planejar e organizar as próximas ações } \\
\text { (formação continuada). }\end{array}$ & $\begin{array}{l}\text { Atividades de formação na Universidade } \\
\text { (estudo, reflexão e preparação para o } \\
\text { planejamento do projeto). Nessa etapa os } \\
\text { integrantes do projeto irão finalizar o } \\
\text { desenho da estrutura da formação, a partir } \\
\text { dos temas levantados e dos demais } \\
\text { interesses dos professores e das } \\
\text { comunidades. Nesse período também } \\
\text { serão definidos os parceiros que realizarão } \\
\text { as formações/oficinas e criado um curso } \\
\text { para certificação dos participantes. }\end{array}$ \\
\hline
\end{tabular}

Fonte: Elaboração própria.

O diagnóstico das realidades foi feito com base em três instrumentos/ fontes de consulta: a) respostas dos diretores a um questionário online sobre a organização e a estrutura escolar; b) memória das reuniões com a equipe pedagógica e membros da comunidade; e c) memória da atividade intitulada "Que escola queremos?" mediada pelas bolsistas e voluntários do projeto, e que ocorria em sala de aula com 
os estudantes enquanto as coordenadoras do projeto reuniam-se com o corpo docente e pedagógico das escolas e comunidade.

Levando em conta as necessidades, interesses e problemas das escolas e o potencial de cooperação que a universidade apresenta para apoiar determinadas demandas, iniciou-se a construção de um curso de formação continuada (Quadro 1 Etapa 4), encerrando assim a primeira fase do projeto de extensão "Saberes e Fazeres do Mar".

Com os desdobramentos da Fase 1 e, em consonância com as Diretrizes Curriculares Nacionais de Educação Ambiental (DCNEA) (Brasil, 2012), o Referencial Curricular do Paraná, as Diretrizes das Escolas do Campo e a Proposta pedagógica das Escolas das Ilhas do Litoral Paranaense, foi criado o curso de formação continuada em "Educação ambiental Marinho-Costeira” (Fase 2).

O curso terá certificação pela UFPR nas modalidades de Extensão para quem não possui graduação e, Especialização, para quem seja graduado. Tem caráter semipresencial, em modelo de Alternância e Itinerância: o Tempo Universidade são encontros presenciais entre cursistas e equipe da universidade, e funciona no modelo de itinerância, no qual os docentes do curso irão até as escolas para atender os cursistas em média uma vez por mês, assim como haverá ocasiões de encontros presenciais coletivos em um único local; e o Tempo Comunidade, que se dá quando os cursistas forem desenvolver os conteúdos da formação no cotidiano da escola/comunidade, e produzir sua pesquisa/material mediados pelos professores. $O$ Tempo Comunidade realiza-se à distância, mediante à interação entre cursistas e professores através do uso de um espaço colaborativo online para cada Unidade Temática. Deste modo, será possível apoiar e complementar os encontros presenciais, assim como os cursistas poderão disponibilizar as atividades realizadas nas comunidades para efeito de acompanhamento e avaliação.

A proposta do curso é que ele ocorra nas escolas durante o período letivo. Portanto, para que se garantam as 800 horas letivas previstas em lei, concomitantemente ao atendimento dos cursistas, o projeto prevê oficinas para aos estudantes das escolas das ilhas, ministradas por profissionais e alunos (bolsistas e voluntários) da Universidade, bem como por pessoas de cada comunidade previamente indicadas e convidadas para ministrar oficinas relativas aos saberes e fazeres do mar. 
O curso de formação continuada foi concebido e estruturado em 4 eixos (ou unidades temáticas):

1. Fundamentos teórico-metodológicos da Educação Ambiental marinho-costeira;

2. Ocupação e uso do território marinho-costeiro;

3. Abordagens teórico-metodológicas dos saberes e fazeres do mar;

4. Educomunicação e produção de material didático-pedagógico.

Para que haja articulação dos eixos (Unidades Temáticas) entre si nas diferentes escolas, haverá um professor-facilitador para cada uma das escolas atendidas pelo curso, assim como serão selecionados cursistas-facilitadores para a articulação entre as escolas. E, como produto, a formação possibilitará, além da oportunidade de planejamentos coletivos e o desenvolvimento da aprendizagem por projetos, a construção de materiais didáticos que contemplem o reconhecimento da realidade socioambiental local e os saberes e fazeres do mar, aliados às áreas do conhecimento e aos eixos temáticos da proposta pedagógica das ilhas.

\section{ALGUMAS REFLEXÕES E DESDOBRAMENTOS INICIAIS}

Conforme abordado anteriormente, o curso de formação continuada em "Educação ambiental Marinho-Costeira" foi planejado para a Fase 2 do projeto de extensão Saberes e Fazeres do Mar. A concepção do curso, tanto na modalidade de especialização como na de extensão, vem de reflexões das coordenadoras do projeto (e autoras deste relato de experiência) sobre a necessidade de se delinear uma formação que incorporasse as dimensões da educação ambiental crítica, concepção teórica comum, às suas áreas de atuação profissional, quais sejam, a Educação do campo e a Oceanografia socioambiental. Apresentam-se, a seguir, as linhas de pensamento que guiaram a criação da proposta em recente funcionamento.

\section{Aproximações entre a Educação do Campo e a Educação ambiental crítica}

A Educação do campo é um processo de luta histórica desencadeada pelos movimentos sociais do campo que visa "incidir sobre a política de educação desde os interesses sociais das comunidades camponesas" (Caldart, 2015: 258). Sendo 
assim, é um campo bastante específico, já que se fundamenta prioritariamente na associação com as questões do desenvolvimento e do território no qual está enraizado. Nesse sentido, como prática social em construção, se caracteriza por ser uma luta social por uma educação específica para e com as comunidades do campo.

A Lei de Diretrizes e Bases da Educação Nacional de 1996 (LDB) (Brasil, 1996), traz um grande avanço para a área, abrindo espaço para que as escolas localizadas no campo pudessem se desvincular do formato das escolas urbanas, podendo adaptar seus currículos, metodologias e calendário às especificidades da vida nas comunidades:

Art. 28: Na oferta de educação básica para a população rural, os sistemas de ensino promoverão as adaptações necessárias à sua adequação às peculiaridades da vida rural e de cada região, especialmente:

I. Conteúdos curriculares e metodologias apropriadas às reais necessidades e interesses dos alunos da zona rural;

II. Organização escolar própria, incluindo adequação do calendário escolar às fases do ciclo agrícola e às condições climáticas;

III. Adequação à natureza do trabalho na zona rural.

É nesse momento político que a Educação do campo passa a ser pensada a partir das especificidades dos povos do campo. No Paraná, uma resolução de 2010 da SEED instituiu a Educação do campo como política pública no estado, objetivando a garantia e a qualidade no atendimento escolar, dando início a um processo de reconhecimento dos povos do campo. Inicia-se assim uma ideia da Educação do campo mais abrangente, configurando-se em um projeto social no qual "a escola está inserida pelo espaço onde se encontra, ou seja, a dinâmica que se estabelece para fazer avançar o desenvolvimento local que poderá ser um dos conteúdos de onde o trabalho da escola parte" (Paraná, 2009: 150).

Ao olhar das políticas públicas, os ilhéus são considerados sujeitos do campo e, nessa perspectiva, as escolas das ilhas no estado do Paraná são compreendidas como Escolas do Campo. Importante enfatizar que as ilhas, por serem altamente suscetíveis a degradações ambientais, possuem especificidades que dificultam um elevado nível de sustentabilidade ambiental. Segundo Souza (2007), além do isolamento geográfico e do ecossistema sensível e frágil, há outras características que compõe essa especificidade, tais como a escassez de fontes de energia e de água potável e o desenvolvimento social e educativo frágil. Além disso, o autor 
destaca que há também um imaginário, a partir da visão dos ilhéus, que deriva essencialmente do distanciamento físico do continente, ou seja, da própria condição da insularidade. Assim, é importante que se entenda as ilhas como porções de territórios construídos, produzidos social e culturalmente: as comunidades que vivem em ilhas exercem diferentes práticas pedagógicas sociais ao longo de gerações (Diegues, 1999). São, dessa forma, constituídos por memórias, identidades, saberes e dinâmicas. Esses modos de vida tradicionais e particulares dos ilhéus encontramse fortemente ameaçados quando aliados à implantação de Unidades de Conservação, que grande parte das vezes desconsideram a presença humana nas áreas.

Estendendo-se o olhar para as desigualdades ainda recorrentes nas escolas do campo, compreende-se que a educação deva participar da formação de sujeitos sociais emancipados, capazes de transformar a realidade e serem livres para construir sua própria existência; sujeitos vistos como seres tanto individuais quanto sociais, historicamente situados. Adotou-se, para o projeto de extensão, a definição de educação embasada em Loureiro (2012: 37): "Educar é emancipar a humanidade, criar estados de liberdade diante das condições que nos colocamos no processo histórico e propiciar alternativas para irmos além de tais condições".

Sauvé (2016: 294) ressalta que, em nível pessoal, a Educação ambiental tem como tarefa construir uma identidade ambiental que possa trazer significado ao nosso ser no mundo, possibilitando "um pertencimento ao meio de vida" e promovendo uma "cultura do engajamento". Nesse sentido, o pertencimento ao lugar é condição necessária para a responsabilidade ambiental. No nível das comunidades, a Educação ambiental pode potencializar dinâmicas sociais que favoreçam a solidariedade, numa perspectiva colaborativa e crítica das realidades.

Nessa linha de pensamento, como um movimento de contracultura, a Educação ambiental, ao mesmo tempo que educa, também intensifica a luta por mudanças sociais. Mudança social entendida aqui como uma maneira de recuperar o protagonismo das pessoas e concretizar o desenvolvimento humano almejado: sustentável, equilibrado e justo (Gómez, Freitas e Callejas, 2007).

Portanto, a Educação ambiental que se almeja no projeto é aquela na qual a prática pedagógica possibilite uma participação efetiva dos estudantes e das comunidades, resultando no envolvimento e na organização de pessoas e grupos 
sociais nas lutas pela melhoria da qualidade vida, que questionam as necessidades materiais simbólicas de consumo e desvelam outras possibilidades de felicidade e de vida.

A Educação ambiental, na perspectiva da transformação social, tem como ponto de partida e chegada a realidade dos estudantes, ou seja, sua prática social. Assim também orientam os princípios da Educação do campo, quando trazem que essa abordagem pode ser considerada uma dívida histórica que a educação tem com os povos do campo, uma vez que, seja pelas políticas da educação, ou mesmo pelos próprios livros didáticos, sofreram e ainda sofrem pressões que procuram "enquadrá-los" aos moldes da vida urbano-industrial, negando suas culturas e necessidades locais.

Considera-se o fortalecimento da dimensão comunitária da escola como uma alternativa para que os ilhéus se percebam e se fortaleçam enquanto coletivo, enfrentando a falta de reconhecimento e valorização de sua cultura, em especial a partir do espaço escolar. Segundo Zakrzevski (2007), é na ação conjunta da escola com a comunidade que se favorece o desenvolvimento social, e nesse caso é importante relembrar que a participação da comunidade na escola pode ser entendida e vivenciada de diferentes maneiras.

\section{A Educação ambiental na perspectiva da Oceanografia Socioambiental}

A incorporação das questões ambientais passou a ser obrigatória em todos os níveis de educação formal no Brasil, desde a promulgação da Política Nacional de Educação Ambiental em 1999. Por outro lado, as demandas da sociedade contemporânea têm apresentado às Ciências do Mar novos desafios em sua capacidade de produzir conhecimentos diversos e, ao mesmo tempo, relacioná-los. A alta complexidade das dinâmicas do Oceano e zonas costeiras requer novos enfoques e métodos de aproximação das diversas áreas do saber, tanto para entendê-las de uma forma abrangente como para que se possam elaborar respostas mais adequadas para a resolução de problemas.

O Curso de Oceanografia da Universidade Federal do Paraná (Campus Pontal do Paraná - Centro de Estudos do Mar), em funcionamento desde o ano 2000, destaca-se por incorporar à formação geral as formas de interação entre 
sociedade, meio ambiente e desenvolvimento, através de disciplinas e conteúdos provenientes das Ciências Humanas e Sociais com enfoque no gerenciamento das atividades humanas em regiões costeiras. É possível observar, através do currículo, a intencionalidade de uma formação interdisciplinar que permita ao estudante compreender a interação entre as ciências naturais e sociais, com especial destaque ao entendimento dos conflitos socioambientais que decorrem das diferentes formas de uso e apropriação dos recursos marinhos e costeiros por diferentes atores sociais.

A chamada "área socioambiental" também está presente no rol de disciplinas profissionalizantes e tem um papel chave na formação de profissionais capazes de integrar às pesquisas no campo das ciências biofísicas as preocupações sociais, ambientais e do desenvolvimento. A presença da disciplina de Educação Ambiental na grade curricular do curso de Oceanografia traz à tona a responsabilidade da universidade em inserir a discussão em todos os níveis de ensino e, em se tratando do Ensino Superior, em todas as áreas de formação profissional, conforme prevêem as Diretrizes Curriculares Nacionais de Educação Ambiental (Brasil, 2012).

O escopo da disciplina de Educação Ambiental em questão leva em consideração a sua origem e concepção na perspectiva socioambiental da Oceanografia, assim como o compromisso da universidade com o seu entorno, principalmente com relação aos interesses das populações que dependem diretamente dos recursos naturais da Baía de Paranaguá, uma vez que este espaço geográfico é propício a instalações portuárias, industriais, atividades pesqueiras e turísticas.

Neste contexto, é pertinente destacar que as modalidades de extensão e pósgraduação do curso de formação continuada, aqui descrito como um desdobramento da Fase 1 do projeto de extensão Saberes e Fazeres do Mar, não por acaso têm características que convergem a Educação do campo e a Educação ambiental na perspectiva da Oceanografia socioambiental. Desse modo, entende-se a Educação Ambiental Marinho-Costeira como uma dimensão que preza pela territorialidade e contexto socioambiental, pelos direitos e pela valorização das especificidades dessa população e dos povos tradicionais, possibilitando o desenvolvimento local sustentável e, consequentemente, sua transformação social, com vistas a uma melhor qualidade de vida. 


\section{RESULTADOS PRELIMINARES}

Para compreender as demandas gerais e específicas das escolas visitadas na primeira fase do projeto foi realizada uma análise estatística dos resultados. Estes ainda estão sendo sistematizados, mas já é possível perceber que as necessidades apresentadas pela comunidade escolar são específicas e complexas. Dentre elas é possível citar: estrutura física precária; falta de materiais didáticos e de internet; alta rotatividade, principalmente por conta das situações de trabalho da maioria dos professores que, além de serem contratados temporariamente, dependem de transporte e estadia; falta de participação da comunidade nos processos escolares e dificuldade de mobilizá-la; a própria organização curricular por área do conhecimento; em alguns casos, a desmotivação dos estudantes cotidianamente; vulnerabilidade das comunidades no que se refere à saúde, saneamento e falta de opções de geração de renda; cursos de formação continuada que não atendem às reais necessidades da escola; falta de opção para continuidade de estudos; etc.

A partir das reflexões preliminares dos resultados da primeira fase do projeto, é crucial destacar dois pontos de extrema vulnerabilidade que a nova organização curricular traz para as escolas das ilhas: a fragilidade da formação disciplinar e a falta de materiais didáticos específicos. Verificou-se que o professor ainda não está preparado para materializar a organização dos conteúdos por área do conhecimento e, ainda, não encontra materiais nem apoio pedagógico ou de formação suficientes.

Com relação ao primeiro ponto, visto que os professores são formados em licenciaturas organizadas por disciplinas, a organização curricular por área do conhecimento desafia-os a transitar pelos temas das disciplinas que compõem a área do conhecimento sobre a qual atuam, mas nas quais não são licenciados.

Rodrigues (2010) sinaliza que a implementação de um currículo por áreas do conhecimento necessita de um processo intenso de formação continuada, para que possa desenvolver todas as suas possibilidades. Segundo o autor,

As áreas do conhecimento devem ser compreendidas muito mais na dimensão da docência, como uma forma de implementar processos interdisciplinares com vista ao desenvolvimento de aprendizagens significativas do que, efetivamente, como forma de produção de conhecimentos científicos (Rodrigues, 2010: 21). 
Essa é uma questão delicada, porque a formação inicial dos professores das licenciaturas ainda se dá de maneira disciplinar. Há, nesse sentido, lacunas na formação dos professores, já "que normalmente ocorre a fragmentação do conhecimento disciplinar levando ou até reforçando concepções antropocêntricas e utilitaristas de ambiente" (Guerra e Taglieber, 2006). Os conteúdos das outras disciplinas que a organização por áreas abarca são contemplados de maneira superficial (Caldart, 2015).

De maneira geral, esse tipo de organização curricular traz embutida uma concepção de educação e de escola ligadas a objetivos formativos mais amplos, ou, nas palavras de Caldart (2015: 10), "como princípio educativo e vinculando os conteúdos escolares com os conteúdos da vida". Nessa perspectiva, as potencialidades da opção por área estão na "desestabilização de uma ordem dada e desnaturalização de uma forma curricular (a disciplinar) que é histórica”, assumida como única possibilidade de se organizar o currículo.

No caso da Educação ambiental, esse tipo de organização curricular pode potencializar a relação dos conteúdos com os saberes e fazeres das comunidades, uma vez que busca superar a fragmentação colocada pela disciplinarização, não somente a partir da interdisciplinaridade, mas de outra maneira de pensar as relações dos próprios conteúdos sistematizados com a vida dos estudantes, dando subsídios mais consistentes para uma ação de transformação das realidades que vivenciam.

Segura (2007: 96) alerta que é comum que, quando pensamos na escola, automaticamente pensemos em disciplinas, em currículo. Entretanto, em um movimento de enfrentamento a essa questão, a pergunta que deveríamos nos fazer é: "como os conteúdos curriculares tratam da realidade?", e não "como inserir a temática ambiental nos conteúdos curriculares?". Quando se toma a realidade dos estudantes como ponto de partida e chegada, abrem-se possibilidades para que as temáticas sejam pensadas a partir das experiências, vivências e desafios vividos cotidianamente pelos sujeitos envolvidos, reorganizando a partir daí as ações didático-pedagógicas e os saberes escolares.

No segundo ponto, em relação aos materiais didáticos, é importante enfatizar que não é tarefa simples modificar uma estrutura curricular quando se tem materiais de apoio ao professor que estão organizados de maneira disciplinar. Nos materiais 
didáticos disponíveis, mais especificamente nos livros didáticos que veiculam nessas escolas, os conteúdos são abordados a partir de outras realidades que não condizem com as maneiras de viver dos povos do campo, corroborando com a observação de Zakrzevski (2004: 81), de que "a extensa maioria dos livros didáticos, recursos fortes nas salas de aula do mundo inteiro, advém de grandes centros urbanos e são de autoria de pessoas que desconhecem outras realidades".

Desde 1994, a primeira versão do Programa Nacional de Educação Ambiental (Brasil, 1994) já assumia a escassa produção e distribuição de materiais didáticos na área ambiental. No entanto, o programa traz como uma das suas missões a promoção e apoio na produção e na disseminação de materiais educativos e didático-pedagógicos, para todos os níveis de ensino, que contemplem as questões socioambientais locais e regionais. Ainda, propõe que seja estabelecida parceria entre o Ministério da Educação e Cultura e o Ministério do Meio Ambiente para aquisição e produção de material referente à temática ambiental, como impressos e audiovisuais, a serem distribuídos para todos os estados. Nessa mesma linha, a Política Nacional de Educação Ambiental (1999) traz como uma das suas linhas de ação a "produção e divulgação de material educativo" e o "apoio a iniciativas e experiências locais e regionais, incluindo a produção de material educativo" (Brasil, 1999).

Reforçando essa ideia, as Diretrizes Curriculares para Educação Ambiental sinalizam a importância da produção e avaliação de materiais didáticos e pedagógicos a serem adotados pelos sistemas de ensino. Além disso, trazem o incentivo à "produção regional de materiais pedagógicos em múltiplas linguagens e suportes tecnológicos e que trabalhem conteúdos voltados para os biomas e para a realidade local, estadual ou regional dos estabelecimentos de ensino" e a "participação de professores e alunos na produção regional dos materiais pedagógicos, reconhecendo-os como produtores de conhecimento a partir da práxis local" (Brasil, 2012: 2).

\section{CONSIDERAÇÕES FINAIS}

Ao findar a primeira fase do projeto, entende-se que se alcançou o objetivo de produzir dados significativos para o levantamento de informações e demandas das 
comunidades escolares, gerando assim subsídios para a continuidade das ações propostas. Os dados serviram de apoio para o planejamento da formação continuada, que está iniciando, sendo planejada e construída coletivamente por uma equipe de professores de onze cursos da UFPR (Setor Litoral e Campus Pontal do Paraná - CEM), buscando articular ações de apoio às problemáticas levantadas nas comunidades por meio de dados oriundos do diagnóstico realizado nas consultas.

Foram realizados diversos diálogos com o campo da Educação e conteúdos de Pedagogia, gestão escolar e realidade escolar, assim como entre os conhecimentos em Educação e Oceanografia e demais áreas que deverão ser abordadas no curso de formação, bem como sua integração para resolução dos problemas identificados. Em relação à participação da comunidade escolar e local em cada ilha atendida, é perceptível o interesse e comprometimento, uma vez que ela está sendo construída com eles, de maneira coletiva, e não para eles.

A proposta apresentada pretende ser desenvolvida de maneira gradativa, a fim de ir abrangendo, a cada ano, mais escolas e mais cursos da UFPR e demais instituições parceiras. Nesse sentido, propõe inicialmente um trabalho de dois anos, para posterior avaliação e continuidade. A avaliação se dará de maneira coletiva, com participação de todos os sujeitos envolvidos, na forma de rodas de conversa e auto avaliação, respeitando a coerência com a concepção teórico-metodológica adotada.

Em um primeiro momento, é perceptível que a valorização dos saberes locais por parte dos estudantes é fator decisivo na educação que visa a emancipação dos sujeitos (Zakrzevski, 2007; Loureiro, 2012; Andreoli, 2016). Trabalhar com a valorização dos conhecimentos que os estudantes possuem sobre o local onde vivem (modos de viver e aspectos ambientais), apresenta-se na Educação ambiental como uma possibilidade de ampliação/aprofundamento da compreensão e do conhecimento a respeito do local que residem e das questões socioambientais presentes nesse contexto, na busca por um olhar crítico, pela participação social e por ações transformadoras. 


\section{REFERÊNCIAS}

ANDREOLI, V. M. A Educação Ambiental no contexto dos colégios estaduais da Ilha do Mel/PR: Currículo, ação docente e desenvolvimento comunitário local. (Tese). Programa de Pós-Graduação em Educação, Setor de Educação, Universidade Federal do Paraná. Curitiba, 2016. 370 f.

BRASIL. Programa Nacional de Educação Ambiental - PRONEA. Diário Oficial, 22 de dezembro de 1994.

. Lei $\mathrm{n}^{\circ} 9.394$, de 20 de dezembro de 1996, estabelece as Diretrizes e bases da educação nacional, Brasília, 1996.

. Lei no9.795, de 27 de abril de 1999. Dispõe sobre a educação ambiental, institui a Política Nacional de Educação Ambiental e dá outras providências. Brasília, 1999.

Decreto Nacional $n^{\circ} 6.040$, de 2007. Institui a Política Nacional de Desenvolvimento Sustentável dos povos e comunidades tradicionais do Brasil. Brasília, 2007.

. Resolução $\mathrm{n}^{\circ} 2$, de 15 de junho de 2012. Estabelece as Diretrizes Curriculares Nacionais para a Educação Ambiental. Brasília, 2012.

CALDART, R. S. Licenciatura em Educação do Campo e projeto formativo: qual o lugar da docência por área? In: CALDART, R. S. et al. (org.). Caminhos para transformação da escola: reflexões desde práticas pedagógicas da Licenciatura em Educação do Campo. São Paulo: Expressão Popular, 2012. p. 127-154.

DIEGUES, A. C. Sociedades insulares e biodiversidade. São Paulo: NUPAUB/USP, 1999.

FARACO, L. F. D.; ANDRIGUETTO FILHO, J. M.; DAW, T.; LANA, P. D. C.; TEIXEIRA, C. F. Vulnerability Among Fishers in Southern Brazil and its Relation to Marine Protected Areas in a Scenario of Declining Fisheries. Desenvolvimento e Meio Ambiente, v. 38, 2016.

GUERRA, A. F. S.; TAGLIEBER, J. E. Formação continuada de educadores ambientais: desafios e possibilidades. Encontro Nacional de Didática e Prática de Ensino - $13^{\circ}$ ENDIPE. 2006.

GÓMEZ, J. A. C.; FREITAS, O. M. P.; CALLEJAS, G. V. Educação e Desenvolvimento Comunitário Local: perspectivas pedagógicas e sociais da sustentabilidade. Porto: Profedições, 2007.

IBIAPINA, I. M. L. M. Pesquisa colaborativa: investigação, formação e produção de conhecimentos. Brasília: Líber Livro Editora, 2008. 
KALIKOSKI, D. C.; ROCHA, R. D.; VASCONCELLOS, M. C. Importância Do Conhecimento Ecológico Tradicional Na Gestão Da Pesca Artesanal No Estuário Da Lagoa Dos Patos, Extremo Sul Do Brasil. Ambiente \& Educação, v.11, n. 1, 2006.

LOUREIRO, C. F. B. Trajetória e Fundamentos da Educação Ambiental. 4 ed. São Paulo: Cortez, 2012.

MENDONÇA, J. T.; LUCENA, A. C. M.; MUEHLMANN, L. D.; MEDEIROS, R. P. Socioeconomia da pesca no litoral do estado do Paraná (Brasil) no período de 2005 a 2015. Desenvolvimento e Meio Ambiente, v. 41, p. 140-157, 2017.

MOURA, Gustavo Goulart Moreira. Águas da Coréia: pescadores, espaço e tempo na construção de um território de pesca na Lagoa dos Patos (RS) numa perspectiva etnooceanográfica. Dissertação de Mestrado. USP. São Paulo - SP. Março, 2009.

PARANÁ. Secretaria de Estado da Educação. Superintendência da Educação. Departamento da Diversidade. Coordenação da Educação do Campo. Proposta pedagógica das Escolas das Ilhas do Litoral Paranaense. Curitiba: SEED/PR., 2009.

Diretrizes Curriculares da Educação do Campo. Curitiba: Secretaria de Estado da Educação - SEED, 2006.

RODRIGUES, R. Reflexões sobre a organização curricular por área de conhecimento. In CALDART, Roseli Salete (org). Caminhos para a transformação da escola. S. Paulo: Expressão Popular, 2010; p 101-126.

SAUVÉ, L. Viver juntos em nossa Terra: Desafios contemporâneos da educação ambiental. Revista Contrapontos - Eletrônica, Vol. 16 - n. 2 - Itajaí, mai-ago 2016.

SEGURA, D. S. B. Educação ambiental nos projetos transversais. In: Vamos cuidar do Brasil: conceitos e práticas pedagógicas em educação ambiental. Brasília: Ministério da Educação, Coordenação Geral de Educação Ambiental: Ministério do Meio Ambiente, Departamento de Educação Ambiental: UNESCO. 2007. 248p.

SOUZA, G. M. R. Impactos socioculturais do turismo em comunidades insulares: um estudo de caso no arquipélago de Fernando de Noronha - PE. Dissertação (Mestrado) - Centro Universitário UMA - Programa de Mestrado em Turismo e Meio Ambiente. Belo Horizonte, 2007. 110 p.

ZAKRZEVSKI, S. B. (org). Conservação e uso sustentável da água: múltiplos olhares. Erechim, RS: EdiFapes, 2007.

Por uma educação ambiental crítica e emancipatória no meio rural Revista brasileira de educação ambiental/Rede Brasileira de Educação Ambiental. n. 0. Brasília: Rede Brasileira de Educação Ambiental, 2004. p. 79-86. 